\title{
TENSÕES E CONFLITO DE VISÕES: A LIBERDADE A PARTIR DOS CLÁSSICOS AO CONSERVADORISMO DE SCRUTON ${ }^{12}$
}

\author{
Danilo Cortez Gomes ${ }^{3}$
}

\begin{abstract}
RESUMO
A complexidade que envolve a condição humana ultrapassa padrões e ideologias políticas que buscam enquadrar a sociedade numa uniformidade não condizente com a pluralidade típica das sociedades modernas, o que faz surgir continuamente tensões entre visões divergentes. Por isso, este ensaio teórico busca discutir as tensões no campo político-social no tocante à liberdade a partir de autores clássicos como Maquiavel, Hobbes, Locke, Rousseau e Mill, bem como a abordagem conservadora de Roger Scruton. Nessa discussão, a liberdade se baseia num sentimento de responsabilidade que deve caracterizar o indivíduo racional, o qual enxerga a sociedade como um território comum em que suas escolhas afetam a si mesmo e os outros, mesmo ciente de que os conflitos e tensões, frutos das diferentes visões ali expostas, não serão extintos.
\end{abstract}

Palavras-chave: Política. Conflito de visões. Liberdade.

\begin{abstract}
The complexity that involves the human condition transcends patterns and political ideologies that seek to frame society in a uniformity that does not correspond to the plurality typical of modern societies, which continually causes tensions between divergent visions. Therefore, this theoretical essay seeks to discuss the tensions in the political-social field in relation to freedom from classic authors such as Machiavelli, Hobbes, Locke, Rousseau and Mill, as well as the conservative approach of Roger Scruton. In this discussion, the freedom is based on a sense of responsibility that should characterize the rational individual, who sees society as a common territory in which his choices affect himself and others, even aware that conflicts and tensions, products of the different views exposed there, will not be extinct.
\end{abstract}

Keywords: Politics. Conflict of views. Freedom.

\section{RESUMEN}

La complejidad que implica la condición humana sobrepasa patrones e ideologías políticas que buscan encuadrar a la sociedad en una uniformidad no acorde con la pluralidad típica de las sociedades modernas, lo que hace surgir continuamente tensiones entre visiones divergentes. Por eso, este ensayo teórico busca discutir las tensiones en el campo político-social en lo que se refiere a la libertad a partir de autores clásicos como Maquiavelo, Hobbes, Locke, Rousseau y Mill, así como el enfoque conservador de Roger Scruton. En esta discusión, la libertad se basa en un sentimiento de responsabilidad que debe caracterizar al individuo racional, el cual ve la sociedad como un territorio común en que sus elecciones afectan a sí mismo y los demás, mismo consciente de que los conflictos y tensiones, frutos de las diferentes visiones allí expuestas, no serán extinguidas. Palabras clave: Política. Conflicto de visiones. Libertad.

\section{INTRODUÇÃO: CONTEXTUALIZANDO O PROBLEMA, OU MELHOR, AS TENSÕES}

Mesmo ciente da dinamicidade e complexidade natural que envolve a história, urge compreender que esse movimento constante proporciona transformações diversas em momentos determinados, ora mais acelerados, ora mais parcimoniosos. Todavia, ao longo do

\footnotetext{
${ }^{1}$ Enviado: 12/04/2017. Aceito: 03/12/2017.

${ }^{2}$ DOI: http://dx.doi.org/10.5380/recp.v9i1.51717

${ }^{3}$ Doutorando em Ciências Sociais. Graduado e Mestre em Administração. Especialista em Gestão Pública. Docente do Instituto Federal de Educação, Ciência e Tecnologia do Rio Grande do Norte. E-mail: danilo.cortez@ifrn.edu.br
} 
GOMES, D. C. Tensões e conflito de visões: a liberdade a partir dos clássicos ao conservadorismo de Scruton

tempo, uma espécie de ziguezague passou a caracterizar a história da humanidade, especialmente no que tange à política, o que a afasta totalmente de uma linearidade ou pensamento padrão para todos os tempos e povos. Dito isto, cabe aos estudiosos hodiernos tentar analisar tais questões, evitando anacronismos e interpretações míopes que deságuem numa defesa ou ataque perene às visões alheias, isto é, às percepções divergentes que não raramente se digladiam no campo intelectual e, consequentemente, nas esferas política e social.

No campo político, esses debates e discussões são comumente acalorados e, na maioria das vezes, sem consensos. Obviamente, seria ingênuo pensar que estamos num ambiente pacífico e favorável ou num jogo em que todos saem vencedores, ou então que os "adversários" podem abrir mão facilmente de suas idéias, convicções e princípios. Ao contrário, o tempo tem contribuído para enaltecer a confirmação de que há uma contínua e latente tensão entre pensamentos opostos, ou seja, entre o marxismo-leninismo e a Escola Austríaca, o comunismo e o liberalismo, o presidencialismo e o parlamentarismo, a democracia e as ditaduras, a monarquia e a república, entre outros.

Atualmente, as tensões e conflitos se mostram mais evidentemente quando da utilização dos termos "esquerda" e "direita" (BOBBIO, 1995; ROTHBARD, 2016), o que não difere muito daquilo que Sowell (2012) afirma sobre as origens ideológicas das lutas políticas a partir do conflito das visões "restrita" e "irrestrita". Assim, uma espécie de movimento pendular caracteriza as sociedades modernas, de forma que a oscilação entre os princípios opostos se torna algo comum. No entanto, surgem questões subjacentes a esses conflitos: há um pensamento aglutinador? E, se há, seria este interessante ao debate e ao desenvolvimento das sociedades? Essas tensões constantes possibilitam o afloramento de outras vertentes até então adormecidas?

Nesse sentido, pode-se dizer que há um contínuo conflito de visões que gera uma constante tensão no que diz respeito aos mais diversos assuntos (SOWELL, 2012), inclusive às discussões sobre a liberdade. Dessa forma, este artigo busca discutir as tensões no campo político-social no tocante à liberdade a partir de autores clássicos que, em suas respectivas épocas, formaram opiniões e alicerçaram o "fazer política" ou establishment de outrora (e, também, dos dias atuais). Além do mais, apresentar-se-á nessa discussão a abordagem conservadora do filósofo britânico Roger Scruton (2015), que sugere uma linha norteadora que não tende demasiadamente nem para a esquerda nem para a direita (o que, porém, não implica neutralidade ou a dizimação de tais conflitos). Para alcançar tal intento, este artigo, além desta parte introdutória, consta de três capítulos, que versam sobre a tensão no conflito 
de visões, para inicialmente contextualizar o problema; as diferentes percepções sobre a liberdade a partir de autores clássicos; e o pensamento conservador na abordagem de Roger Scruton. Por fim, há, ainda, as considerações finais sobre a discussão ora realizada.

\section{CONTEXTUALIZANDO O PROBLEMA: A TENSÃO NO CONFLITO DE VISÕES}

Diante dos conflitos e tensões existentes, cabe inicialmente compreender as características dessas concepções ou visões. Para isso, o livro do filósofo e político norteamericano Thomas Sowell sobre as origens ideológicas das lutas políticas traz um ponto de partida interessante, especialmente quando se faz um esforço para se alcançar um verdadeiro entendimento a respeito daquilo que o outro pensa e quais as motivações que o levam a pensar e agir dessa forma. De acordo com Sowell (2012, p. 18), “uma visão é nossa percepção de como o mundo funciona". O autor não faz apologia de uma ou outra concepção, mas aborda duas visões - restrita e irrestrita - com suas especificidades, enfatizando que estas influenciam consideravelmente as sociedades:

\footnotetext{
Visões sociais são importantes de várias formas. O mais evidente é que políticas baseadas em uma determinada visão de mundo têm consequências que se espalham pela sociedade e reverberam durante anos, ou mesmo por gerações ou séculos. Visões determinam os temas tanto para o pensamento quanto para a ação. Elas preenchem necessariamente as grandes lacunas do conhecimento do indivíduo. (SOWELL, 2012, p. 21).
}

Nesse contexto, essas diferentes percepções em relação à concepção do homem e do mundo não se traduzem apenas em conclusões divergentes e totalmente opostas que envolvem questões de justiça, liberdade ou guerra, mas na verdadeira causa dos contínuos conflitos entre essas visões - ou seja, a tensão contínua não está perto de ser amenizada, pois enquanto a visão restrita é uma visão trágica da condição humana, a visão irrestrita é uma visão moral das intenções humanas, que são vistas como finalmente decisivas. Desse modo, a visão irrestrita promove a busca dos mais altos ideais e das melhores soluções, enquanto a visão restrita vê o "melhor" como inimigo do "bom".

A respeito do estado de natureza, a visão restrita entende a natureza humana como essencialmente inalterada ao longo do tempo e em todo o mundo, e as expressões culturais específicas das necessidades humanas peculiares a determinadas sociedades não são vistas como prontas e beneficamente variáveis mediante intervenção forçada. Por outro lado, os 
GOMES, D. C. Tensões e conflito de visões: a liberdade a partir dos clássicos ao conservadorismo de Scruton

partidários da visão irrestrita tendem a ver a natureza humana como beneficamente mutável e os hábitos sociais como resquícios supérfluos do passado (SOWELL, 2012).

A visão restrita tende mais ao que chamamos de "pensamento liberal", que é pautado em diversas características desse tipo de visão. Ainda, segundo Sowell (2012, p. 86), "a visão restrita não é uma visão estática do processo social, tampouco uma visão de que o status quo deveria ser alterado. Pelo contrário, seu princípio central é a evolução”. Em alguns momentos, é comum certa confusão na distinção entre o liberalismo e o conservadorismo, como se estes formassem um único movimento, diferentemente da abordagem dada por Roger Scruton, que veremos mais adiante.

No tocante aos campos econômicos e sociais, a visão irrestrita tende, historicamente, a criar condições econômicas e sociais mais igualitárias na sociedade, mesmo quando os meios escolhidos para tal implicam uma grande desigualdade em relação ao direito de decidir sobre essas questões. Porém, de acordo com Sowell (2012, p. 68), “os adeptos da visão restrita, na maioria das vezes, tendem a se preocupar menos com a promoção da igualdade econômica e social e mais com os perigos de uma desigualdade de poder, produzindo uma elite governante articulada composta por racionalistas". Nessa linha de raciocínio, a visão restrita vê as economias de mercado como receptivas a forças sistêmicas - a interação de inúmeras escolhas individuais e realizações —, enquanto a visão irrestrita argumenta que não é assim o funcionamento da economia, na qual normalmente o poder de interesses particulares é respeitado e, portanto, deveria no futuro respeitar o poder do interesse público, inclusive com a forte intervenção do Estado". Aqui, já observamos explicitamente a tensão que diz respeito à intervenção estatal (esquerda) e à não intervenção estatal (direita).

Para melhor ilustrar essa questão, vale apontar os pensamentos opostos a respeito dessas duas visões sobre a liberdade, a começar pelo de Marx e Engels (1998), ao dizerem que a liberdade se traduz na prática dos indivíduos por meio da criação, em situações específicas em que as aptidões e faculdades humanas sejam de fato utilizadas. Para isso, fazse necessária a manifestação real dessas ações num mundo material — isto é, o resultado dessa liberdade se dá na prática do indivíduo, o que é algo difícil de se realizar no sistema capitalista de produção, segundo a concepção marxista, que critica também os princípios metafísicos relacionados à liberdade. Já na corrente liberal, Merquior (2014) apresenta uma relação íntima entre a autonomia e a liberdade ao elencar quatro tipos de materializações da autonomia no decorrer da história, que são: a liberdade de opressão como interferência arbitrária; a liberdade política; a liberdade de consciência e crença; e a liberdade de realização 
pessoal. De forma mais específica e numa tentativa de classificar a direita e a esquerda em relação à liberdade, Bobbio (1995, p. 117) diz:

No que diz respeito à definição de esquerda e direita, a distinção entre as duas díades (igualdade-desigualdade e liberdade-autoridade) adquire particular relevância, pois um dos modos mais comuns de caracterizar a direita em relação à esquerda é contrapondo a direita libertária à esquerda igualitária.

Todavia, essa distinção é muito "simplista", pois existem doutrinas e movimentos libertários tanto na esquerda quanto na direita. Dessa forma, o autor utiliza o critério da postura diante da liberdade para distinguir esses movimentos em quatro partes, a saber: extrema esquerda - igualitária e autoritária; centro-esquerda - igualitária e libertária; centro-direita - libertária e inigualitária; e extrema direita — antiliberal e inigualitária (BOBBIO, 1995).

Retomando a discussão iniciada por Sowell (2012), a liberdade é definida de forma diferente pelas duas visões. Para a visão restrita, a liberdade é uma característica do processo — a ausência de impedimentos externamente impostos —, mas não está necessariamente livre das restrições ou obrigações de determinadas circunstâncias. Por outro lado, para a visão irrestrita a liberdade inclui tanto a ausência de impedimentos diretos, externamente impostos, quanto de limites circunstanciais que reduzam a gama de escolhas dos indivíduos (o que torna essa definição de liberdade bem mais abrangente do que a primeira). Assim, as distinções entre esses conceitos refletem substancialmente nas visões políticas e sociais da sociedade, as quais, por sua vez, alicerçam ainda mais as tensões e conflitos entre pensamentos divergentes.

\section{A LIBERDADE QUE LIBERTA E APRISIONA: DIFERENTES PERCEPÇÕES PARA O MESMO PROBLEMA}

Analisar textos clássicos é paradoxal: ao mesmo tempo em que tal atividade se configura como uma tarefa árdua, é caracterizada por ser algo fácil, pois muito já foi escrito sobre tais autores. Neste artigo não se pretende adentrar minuciosamente na complexidade das obras e de seus correspondentes autores, mas elencar alguns pontos importantes sobre a temática da liberdade, a começar pelos textos de Maquiavel e, em seguida, pelos de Hobbes, Locke, Rousseau e Mill.

Partindo do pressuposto de que o Estado deve ser a instituição que garante o bemestar e segurança dos seus cidadãos, Maquiavel (2006) não acredita que cabe a esse mesmo Estado nutrir um senso de moralidade junto aos seus cidadãos, pois os fins justificam os 
GOMES, D. C. Tensões e conflito de visões: a liberdade a partir dos clássicos ao conservadorismo de Scruton

meios, isto é, a noção de utilidade se sobrepõe aos conceitos de "certo" e "errado", o que extingue qualquer ideologia própria ou retidão moral. Sobre esta última característica, o autor italiano é tido como um pensador moderno justamente por separar a política da moral, rompendo com os princípios políticos e morais judaico-cristãos. A época conturbada em que viveu Maquiavel influenciou sua percepção a considerar a "verdade efetiva das coisas" (construção e conservação do poder) e, consequentemente, a desdenhar do pensamento medievalista do "dever ser", haja vista o grande número de manuais políticos que continham “idealismos”. A visão prática e realista de Maquiavel, que continha a concepção do homem como egoísta, dissimulado e ambicioso, fez com que ele entendesse que até mesmo o engano e a traição podem ser necessários e úteis para se garantir o futuro do Estado, que se traduz na manutenção do bem-estar da e segurança de seus cidadãos, como afirma Abreu (2008, p. 87):

Deve-se compreender que um príncipe, e sobretudo um príncipe novo, não pode praticar todas aquelas coisas pelas quais os homens são considerados bons, uma vez que, frequentemente, é obrigado, para manter o Estado, a agir contra a fé, contra a caridade, contra a humanidade, contra a religião.

Ademais, Maquiavel é tido como um autor republicano, pois acreditava que a violência precisava ser administrada. De forma particular, pode-se encontrar nos "Comentários sobre a primeira década de Tito Lívio" (1982) um projeto normativo que diz respeito à construção da República. No tocante à liberdade, Abreu (2008) enfatiza que esta não é, para Maquiavel, somente um atributo dos cidadãos, mas também das comunidades políticas, e que são as repúblicas as formas de governo mais adequadas para que essas comunidades políticas possam ser livres. Em contrapartida, a ausência da liberdade está relacionada diretamente à corrupção daqueles que ocupam cargos no governo:

\begin{abstract}
A ausência de liberdade está relacionada com as formas de relações de dominação no interior da república e o governo desordenado, obviamente, é aquele que é utilizado não para o bem da comunidade, mas no interesse daqueles que ocupam seus cargos ou de grupos favorecidos, o que pode ocorrer não só com os mecanismos de favorecimento diretos deste ou daquele grupo de cidadãos, mas com decisões equivocadas, que podem sê-lo principalmente quanto ao tempo. (ABREU, 2008, p. 56).
\end{abstract}

A autora observa que a liberdade, na obra de Maquiavel, é um problema de todas as formas de governo, mas que na república há maiores possibilidades de se dispor de mecanismos que evitem a corrupção e, ao mesmo tempo, canalizem os esforços das instituições para os interesses dos cidadãos. 
Na célebre obra de Thomas Hobbes escrita durante a Guerra Civil Inglesa, "Leviatã", percebe-se que a visão do estado de natureza foi influenciada por esse período turbulento, instável e "selvagem", pois, na sua concepção, o indivíduo age em detrimento de seu benefício próprio:

\begin{abstract}
Afinal, as leis naturais (tais como justiça, a equidade, a modéstia, a piedade, enfim, o que determina que façamos aos outros o que queremos que nos façam) são contrárias a nossas paixões naturais, que nos inclinam para a parcialidade, o orgulho, a vingança e coisas semelhantes, se não houver o temor de algum poder que nos obrigue a respeitá-las. (HOBBES, 2014, p. 138).
\end{abstract}

Nesse estado de natureza, todos os homens se encontram em estado de guerra uns contra os outros, e suas vidas são baseadas no medo de seus companheiros. Para Hobbes, a vida da sociedade é totalmente instrumental, sendo excluída a ideia de cooperação, pois todas as relações entre os indivíduos são instrumentais. Assim, para que esse estado de natureza seja ultrapassado, o povo deve se relacionar sob o jugo de um poder soberano: um governante absoluto chamado "Estado" que detenha poderes indivisíveis e ilimitados, os quais serão imprescindíveis para se prevenir a guerra e o caos entre os indivíduos: "A multidão assim unida numa só pessoa passa a chamar-se Estado (em latim, Civitas). Essa é a geração do grande Leviatã, ou, antes (para usarmos termos mais reverentes), daquele deus mortal a quem devemos, abaixo do Deus imortal, nossa paz e defesa" (HOBBES, 2014, p. 142). O Estado precisa ter o controle das opiniões, não podendo haver um poder acima desse governo absoluto. Aqui, no entanto, surge a indagação: esse controle cerceia as individualidades ou não? Num trecho do "Leviatã", Hobbes (2014, p. 80) diz:

\footnotetext{
O maior de todos os poderes humanos é o poder integrado de vários homens unidos com o consentimento de uma pessoa natural ou civil: é o poder do Estado ou aquele de um representativo número de pessoas, cujas ações estão sujeitas à vontade de determinadas pessoas em particular, como é o poder de uma facção ou de várias facções coligadas. Assim, ter servos é poder, como também ter amigos, por isso significa união de forças.
}

Estaria esse governo soberano intrinsecamente vinculado à liberdade dos indivíduos que por meio do consentimento concedem ao Estado tal poder? Essa é uma questão delicada, principalmente para quem defende o absolutismo. Entretanto, faz-se necessário compreender que, segundo Hobbes (2014, p. 111), “caso não haja leis para regular a vida social, a tendência do homem é a barbárie”. Se partirmos do pressuposto de que os homens são bons, o Estado é supérfluo. Porém, isso é, na concepção de Hobbes, uma utopia: 
GOMES, D. C. Tensões e conflito de visões: a liberdade a partir dos clássicos ao conservadorismo de Scruton

Se pudéssemos imaginar uma grande multidão de indivíduos concordes quanto à observância da justiça e das outras leis naturais, sem um poder comum que os mantivesse a todos em atitude de respeito, poderíamos supor que todo o gênero humano fizesse o mesmo e, então, não existiria nem seria preciso que existisse qualquer governo civil ou Estado, pois haveria paz sem sujeição alguma. (HOBBES, 2014, p. 139-140).

Desse modo, quando o indivíduo transfere um direito (e essa transferência ocorre por meio de um contrato) ou renuncia a ele, mesmo que na esperança de ser beneficiado de alguma forma, esse ato é um ato voluntário, que relaciona-se justamente com o que Hobbes fala sobre o direito natural:

O direito natural, a que muitos autores comumente chamam jus naturale, é a liberdade que cada homem tem de utilizar seu poder como bem lhe aprouver, para preservar sua própria natureza, isto é, sua vida; consequentemente, é a liberdade de fazer tudo aquilo que, segundo seu julgamento e razão, é adequado para atingir esse fim. (HOBBES, 2014, p. 110-111).

Sobre esse ato voluntário e consentido, Rousseau (2006, p. 21) afirma, de forma semelhante: "Esses [indivíduos] nascem homens e livres, sua liberdade lhes pertence, ninguém tem o direito de dispor dela, exceto eles próprios". Em suma, Hobbes (2014) traz a seguinte questão: por que precisamos do Estado? E expõe imediatamente a resposta: porque sozinhos não temos condições de nos regular. Por isso, "a causa final, fim ou desígnio dos homens (que apreciam, naturalmente, a liberdade e o domínio sobre os outros), ao introduzir a restrição a si mesmos que os leva a viver em Estados, é a preocupação com sua própria conservação e a garantia de uma vida mais feliz" (HOBBES, 2014, p. 138). Não importa se essa liberdade é considerada "limitada" ou não tão livre como se deseja. Urge dizer que essa liberdade é essencial para a sobrevivência dos indivíduos de natureza frágil e com tendências para a corrupção, os quais mesmo diante de um soberano com poder ilimitado estão a salvo. Assim, há um "mal menor" a ser levado em consideração:

E mesmo que, a respeito desse poder ilimitado [do Estado], os homens possam imaginar muitas consequências desfavoráveis, se tal poder não existisse, as consequências seriam bem piores, como a guerra perpétua dos homens contra seus vizinhos. A condição do homem, nesta vida, sempre terá inconvenientes, mas num Estado jamais se verifica um grande inconveniente, a não ser os que derivam da desobediência dos súditos, e do rompimento daqueles pactos aos quais o Estado deve sua existência. (HOBBES, 2014, p. 169).

Pode-se dizer que há em Hobbes, ainda, uma tensão entre o prenúncio do liberalismo e a democracia, ao passo que sua teoria do estado de natureza não confia no altruísmo do homem. Essa é uma questão sutil, pois a liberdade pode existir, desde que com a ausência da 
lei que "aprisiona" ou limita sua ação, já que por "liberdade" o autor entende "a ausência de empecilhos externos, que podem, muitas vezes, tirar parte do poder de cada um de agir como quiser, mas não impedir que cada pessoa use o poder restante de acordo com seu julgamento e razão" (HOBBES, 2014, p. 111).

Enquanto Hobbes acreditava num certo absolutismo, o filósofo inglês John Locke defendia a limitação dos poderes e das funções do governo. Este, opondo-se ao governo absolutista, argumentava que o governo deveria representar o povo por meio da proteção dos seus direitos à vida, à liberdade, à saúde e à propriedade. Em sua obra "Segundo tratado sobre o Governo Civil”, há a ideia do estado de natureza que traz em seu cerne a liberdade como direito natural, uma liberdade que não se confunde com a total permissividade:

[...] o homem desfruta de uma liberdade total de dispor de si mesmo ou de seus bens, mas não de destruir sua própria pessoa, nem qualquer criatura que se encontre sob sua posse, salvo se assim o exigisse um objetivo mais nobre que a sua própria conservação. O "estado de Natureza" é regido por um direito natural que se impõe a todos, e com respeito à razão, que é este direito, toda a humanidade aprende que, sendo todos iguais e independentes, ninguém deve lesar o outro em sua vida, sua saúde, sua liberdade ou seus bens. (LOCKE, 2001, p. 36).

Os indivíduos são seres racionais e independentes que possuem direitos naturais. Nessa perspectiva, esses mesmos indivíduos se organizam em uma sociedade política baseada num estado de direito que possa garantir sua proteção. Entretanto, pode-se questionar: por que o homem que é tão livre em seu estado de natureza renunciaria à sua liberdade, sujeitando-se à dominação e ao controle de qualquer outro poder? Segundo Locke (2001, p. 69), “a resposta é evidente: ainda que no estado de natureza ele tenha tantos direitos, o gozo deles é muito precário e constantemente exposto às invasões de outros". Para este autor, "o grande objetivo dos homens quando entram em sociedade é desfrutar de sua propriedade pacificamente e sem riscos, e o principal instrumento e os meios de que se servem são as leis estabelecidas nesta sociedade" (LOCKE, 2001, p. 71). Assim, o objetivo primordial da lei é garantir a preservação e o aumento da liberdade - liberdade esta que emana da razão promulgada na lei, diferente de uma liberdade "desenfreada". Por isso, a máxima "onde não há lei não há liberdade" torna-se uma sentença básica em seu pensamento:

Mas a liberdade dos homens submetidos a um governo consiste em possuir uma regra permanente à qual deve obedecer, comum a todos os membros daquela sociedade e instituída pelo poder legislativo nela estabelecido É a liberdade de seguir minha própria vontade em todas as coisas não prescritas por esta regra; e não estar sujeito à vontade inconstante, incerta, desconhecida e arbitrária de outro homem: como a liberdade natural consiste na não submissão a qualquer obrigação exceto a da lei da natureza. (LOCKE, 2001, p. 41). 
GOMES, D. C. Tensões e conflito de visões: a liberdade a partir dos clássicos ao conservadorismo de Scruton

Diferentemente de Hobbes, Locke não concebe o homem em um estado de natureza semelhante ao estado de guerra, mas entende a instituição do governo como um verdadeiro instrumento para conter a parcialidade e a violência dos homens, que são as inconveniências típicas da humanidade. Além do mais, o autor enfatiza a importância do consentimento dos indivíduos enquanto característica essencial da liberdade, inclusive sob o ponto de vista da determinação e da vontade da maioria, pois "todo homem é naturalmente livre e nada pode submetê-lo a qualquer poder sobre a terra, salvo por seu próprio consentimento" (LOCKE, 2001, p. 67). Nessa linha de raciocínio, o consentimento, que é uma premissa básica da liberdade, traz à tona a legitimidade de qualquer sociedade:

Assim, o ponto de partida e a verdadeira constituição de qualquer sociedade política não é nada mais que o consentimento de um número qualquer de homens livres, cuja maioria é capaz de se unir e se incorporar em uma tal sociedade. Esta é a única origem possível de todos os governos legais do mundo. (LOCKE, 2001, p. 62).

A filosofia política de Locke ficou conhecida pelo nome de "liberalismo", alicerce para as revoluções ocorridas no final do século XVIII na França e na América do Norte. No esteio desta filosofia, encontra-se também o suíço Jean-Jacques Rousseau. Ao contrário de Hobbes, Rousseau entendia que o estado de natureza era baseado em pessoas satisfeitas, livres e felizes, e que entregar a liberdade a outra pessoa era impossível sem uma renúncia da própria gênese humana. $\mathrm{Na}$ sua famosa frase que inicia o seu principal texto, "O contrato social”, Rousseau (2006, p. 14) evidencia que "o homem nasceu livre e em toda parte se encontra sob ferros. Acredita-se de tal modo senhor dos outros que não deixa de ser mais escravo que eles". Dessa forma, o contrato social já idealizado em Hobbes, com o intuito de garantir a paz e evitar o estado de natureza por ele concebido, surtiu o efeito apenas de preservar as desigualdades entre os indivíduos e, consequentemente, de destruir sua humanidade pessoal. Entretanto, em "O contrato social”, Rousseau vai além da concepção de Hobbes sobre os efeitos da lei: enquanto, para Hobbes, a lei servia apenas como uma limitação e a liberdade estava sujeita à ausência da lei, Rousseau (2006) entendia que a liberdade podia ser conquistada dentro dos limites desta lei (ROUSSEAU). Nesse quesito, o Estado será o grande protagonista no alcance da liberdade, desde que o povo se torne soberano. Sowell (2012, p. 44), ao explicar o conflito de visões, corrobora com essa ideia de Rousseau, ao afirmar que 
Quando Rousseau disse que o homem "nasceu livre", mas "está acorrentado por todas as partes", ele expressou a essência da visão irrestrita, na qual o problema fundamental não é a natureza ou o homem, mas as instituições. De acordo com Rousseau, "homens não são naturalmente inimigos". A visão diametralmente oposta foi apresentada na obra Leviatã, de Hobbes, em que o poder armado das instituições políticas foi o que evitou a guerra de cada um contra todos que existiria entre os homens em seu estado natural, em que a vida seria "solitária, pobre, repugnante, selvagem e curta".

Ainda sobre esse assunto, Scruton (2015a) dirá que os seguidores de Rousseau acreditavam que essa liberdade, uma vez obtida, se expressaria na felicidade e na irmandade da humanidade, e não na guerra de todos contra todos que Hobbes tinha descrito como o verdadeiro estado de natureza. O Estado legítimo proporcionaria ao povo uma liberdade ainda maior do que aquela usufruída no estado de natureza, permitindo que as pessoas fossem iguais e surgindo, então, a premissa da igualdade que deve servir de base a todo sistema social:

É que, em lugar de destruir a igualdade natural, o pacto fundamental substitui, ao contrário, por uma igualdade moral e legítima a desigualdade física que a natureza poderia ter disposto entre os homens, fazendo com que esses, embora pudessem ser desiguais em força ou em talento, tornem-se iguais por convenção e de direito. (ROUSSEAU, 2006, p. 36).

A partir de então, igualdade e liberdade caminharão juntas, servindo tal unidade, inclusive, de referência para pensadores futuros, pois o maior de todos os bens, nesse contexto do contrato social, se resume nesses dois objetivos: "a liberdade, porque toda dependência particular é outra tanta força subtraída ao corpo do Estado; a igualdade, porque a liberdade não pode substituir sem ela" (ROUSSEAU, 2006, p. 64).

O "novo" contrato social proposto por Rousseau extingue a liberdade natural e conduz a uma liberdade civil que permite ao indivíduo usufruir de tudo aquilo que possui, com base na prescrição da lei, que agora torna-o mais livre do que nunca. Destarte, o filósofo suíço questiona e responde a respeito do Estado: "O que é, portanto, o governo? Um corpo intermediário estabelecido entre os súditos e o soberano para sua recíproca correspondência, encarregado da execução das leis e da manutenção da liberdade, tanto civil como política" (ROUSSEAU, 2006, p. 70). Nesse momento, fica ainda mais evidente que a legitimidade do Estado parte do pressuposto da liberdade e do consentimento dos indivíduos em determinada sociedade, pois os membros do Estado só se tornam livres e cidadãos quando a vontade de todos os membros é a vontade da maioria, que atua com soberania.

O londrino John Stuart Mill, considerado um dos filósofos mais influentes do século XIX, traz em sua obra a questão da liberdade, especialmente em "Ensaio sobre a liberdade". 
GOMES, D. C. Tensões e conflito de visões: a liberdade a partir dos clássicos ao conservadorismo de Scruton

Para Mill, a liberdade de pensamento e ação, desde que não cause dano a outrem, é um princípio inalienável em uma sociedade saudável, visto que "não é ao progresso que nos opomos; pelo contrário, nos vangloriamos de ser o povo mais progressista que jamais viveu. É a individualidade contra a qual lutamos" (MILL, 2006, p. 102). As três liberdades básicas expostas por Stuart Mill compreendem a liberdade de pensamento e ideias, a liberdade de buscar os próprios gostos e objetivos e a liberdade de associação entre os indivíduos:

Esta, então, é a área apropriada da liberdade humana. Ela compreende, primeiro, o domínio interno da consciência; liberdade de pensamento e sentimento; absoluta liberdade de opinião e sentimento sobre todos os assuntos, práticos ou especulativos, científicos, morais ou teológicos [...] Em segundo lugar, o princípio de gosto e objetivos [...] Em terceiro lugar, a partir desta liberdade de cada indivíduo, segue-se a liberdade, dentro dos mesmos limites, de associação dentre indivíduos. (MILL, 2006, p. 30-31).

$\mathrm{Na}$ obra desse autor, o progresso está intimamente associado à liberdade, pois "nenhuma sociedade na qual estas liberdades não sejam, no todo, respeitadas, é livre, qualquer que seja sua forma de governo; e nenhuma será completamente livre se não houver liberdade absoluta e irrestrita" (MILL, 2006, p. 31). Por outro lado, o filósofo britânico faz uma diferenciação entre a liberdade no que diz respeito à conduta entre os indivíduos e à conduta de forma individual:

Na conduta de seres humanos em relação a outros, é necessário que regras gerais sejam observadas pela maioria, a fim de que as pessoas possam saber o que devem esperar; mas nos próprios interesses de cada pessoa, sua espontaneidade individual tem o direito do livre exercício. (MILL, 2006, p. 109).

No entanto, com a tirania da maioria, essa individualidade pode ser prejudicada, sendo, inclusive, esta tirania sancionada pelo governo com o apoio da maioria. Surgem, portanto, as pertinentes questões permeadas de conflitos e tensões: "Qual, então, é o limite correto para a soberania do indivíduo sobre si mesmo? Onde a autoridade da sociedade começa? Quanto da vida humana deve ser atribuído à individualidade, e quanto à sociedade?" (MILL, 2006, p. 107). O próprio autor concebe a resposta na perspectiva liberal:

Tão logo qualquer parte da conduta de uma pessoa afete prejudicialmente os interesses de outros, a sociedade terá jurisdição sobre tal, e a questão do bem-estar geral ser ou não promovido por sua interferência, torna-se aberta à discussão. Mas não há nenhum espaço para abrigar tal questão quando a conduta de uma pessoa não afetar os interesses de outras pessoas além dela própria, ou não precisar afetá-las a menos que elas queiram (todas as pessoas envolvidas estando na maioridade, e com uma quantidade média de compreensão). Em todos esses casos, deve haver liberdade 
perfeita, legal e oficial, para realizar a ação e suportar as consequências. (MILL, 2006, p. 108).

Porém, diante da perspectiva liberal de Mill, há um limite a ser observado: a liberdade não pode ser confundida com permissividade, pois "sempre que há um dano definido, ou um risco de dano definido, seja a um indivíduo ou ao público, o caso deve ser retirado do âmbito da liberdade e colocado naquele da moralidade ou da lei” (MILL, 2006, p. 116), ou seja, esse conflito/tensão deve ser resolvido por meio da razão da lei, que é definida pela maioria e por meio do Estado.

De forma sucinta, buscou-se elencar alguns pontos importantes sobre a liberdade nos pensamentos de Maquiavel, Hobbes, Locke, Rousseau e Mill. Alguns detalhes os diferenciam, mas é importante observar que todos eles enfatizam, de algum modo, a necessidade de um soberano, um governo ou um Estado como instrumento de legitimação, propagação e manutenção da liberdade. $\mathrm{Na}$ verdade, sabe-se que esses autores influenciaram o establishment e as ideologias políticas que se sucederam nos últimos séculos, em especial a partir da Revolução Francesa. A questão é que a liberdade continua sendo um objetivo central dessas ideologias, que comumente se manifestam de formas totalmente opostas em busca do mesmo objetivo. Dessa maneira, as tensões e os conflitos se tornam cada vez mais latentes, dando condições para que o movimento pendular das sociedades modernas se torne consideravelmente acelerado, tais quais as mudanças do mundo atual.

\section{O PENSAMENTO CONSERVADOR DE ROGER SCRUTON}

Por fim, apresenta-se, nesta discussão, a abordagem conservadora do filósofo britânico Roger Scruton, que sugere uma linha norteadora que não implica necessariamente uma neutralidade ou a dizimação dos conflitos existentes.

De acordo com o Scruton (2015a, p. 48), “a liberdade genuína emerge apenas quando o 'eu' é transcendido, e o conflito é resolvido em um estado de reconhecimento mútuo. Cada lado então renuncia à luta de vida e morte que os havia escravizado e respeita a realidade da vontade do outro". Na concepção do autor, esse reconhecimento mútuo se dá pelas instituições que apresentam suas respectivas leis. Aqui, a liberdade está vinculada à associação do "eu" com o "nós"; caso contrário, isto é, com a destruição do Estado, a liberdade se torna tão "solta" que induz ao caos: "a Revolução Francesa é apenas um dos muitos eventos históricos que nos demonstram que os movimentos de libertação, quando conseguem destruir o Estado, primeiro levam à anarquia, depois à tirania e, a seguir, ao terror 
GOMES, D. C. Tensões e conflito de visões: a liberdade a partir dos clássicos ao conservadorismo de Scruton

totalitário" (SCRUTON, 2015a, p. 53-54), pois, no planejamento de cima para baixo que estabelecia uma sociedade livre, igualitária e fraterna, cujos objetivos contêm em si uma profunda contradição, era evidente que, se as pessoas tivessem liberdade, estas a utilizariam de forma a conduzi-las por sua própria vontade rumo à desigualdade. Ainda, deve-se mencionar a pretensão de que as pessoas fossem iguais, o que culminaria na eliminação da própria liberdade. Ademais, os discursos relacionados aos direitos individuais deslocaram-se das liberdades para reivindicações que transformaram a igualdade de tratamento numa igualdade de resultados. Aquilo que outrora foi introduzido na origem da ideia de direitos humanos passou a exigir não uma limitação do poder do Estado, mas um aumento cada vez maior de sua intervenção, para atender às inúmeras reivindicações da sociedade, inclusive as das minorias.

Ainda nesse aspecto, o filósofo britânico explica a visão de Adam Smith que se tornou o ponto central do liberalismo atual, de acordo com a qual na agenda liberal encontrase o controle do Estado, diferentemente do pensamento equivocado do senso comum a respeito de tal visão:

Quando Adam Smith tornou a liberdade central em sua visão da economia moderna, ele deixou claro que a liberdade e a moralidade são dois lados de uma mesma moeda. Uma sociedade livre é uma comunidade de seres responsáveis, unidos pelas leis de solidariedade e pelas obrigações do amor familiar. Não é uma sociedade de pessoas libertas de todas as limitações morais, pois isso é precisamente o oposto de uma sociedade. Sem limitações morais não pode haver cooperação, nenhum compromisso familiar, nenhuma perspectiva de longo prazo, nenhuma esperança de ordem econômica e muito menos de ordem social [...]. Dessa forma se molda a nova agenda liberal: o controle do Estado sobre todos os aspectos da vida pública; total liberdade na esfera privada. (SCRUTON, 2015a, p. 144-145).

O autor aponta algumas falácias típicas de visões ideológicas que deturpam a realidade, principalmente quando perseguem uma determinada utopia. Naquilo que ele chama de "falácia utópica", a utopia é um estado em que não podemos chegar e, por isso, esse ideal — geralmente contraditório e irrealizável - estará sempre imune a refutações, não admitindo qualquer tipo de contestação. Scruton afirma que, geralmente, quem defende essas utopias são aqueles que ele chama de "otimistas inescrupulosos". Para contrapor esses argumentos utópicos, o autor defende um conservadorismo cujo olhar se volta para o futuro e, também, para o passado, pois este já é por todos conhecido:

Assim como o passado contém o futuro, porém, também o futuro requisita o passado. O passado, tal como o cidadão o entende, é o passado orientado para o futuro. A continuidade é um fim seletivo, que olha tanto para trás como para frente com certa desconfiança. Devemos, no entanto, nos lembrar do lugar distintivo do 
passado no nosso entendimento prático: ao contrário do futuro, o passado é conhecido. Como, então, ele poderia entrar em nossas previsões políticas? (SCRUTON, 2015c, p. 84).

Os conservadores depositam sua fé em sistemas conhecidos e testados e desejam impregná-los com toda a autoridade necessária para constituir um domínio público aceito e objetivo. É daí que surge seu respeito pela tradição e pelos costumes e não de qualquer fim - como a liberdade. (SCRUTON, 2015c, p. 75).

Por essa razão, entende-se a preocupação do autor no cultivo do "pessimismo", quando utiliza argumentos favoráveis ao conservadorismo, especialmente no livro "As vantagens do pessimismo: e o perigo da falsa esperança" (SCRUTON, 2015a). A visão pessimista de Scruton se assemelha ao termo "realista esperançoso" de Ariano Suassuna, haja vista o otimista, para este autor, ser um tolo, e o pessimista, um chato.

Por outro lado, longe das características de seus pessimistas e dos "realistas esperançosos" de Ariano Suassuna, o britânico enfatiza o grupo dos "otimistas inescrupulosos", que defendem tanto o liberalismo quanto o socialismo (ou seja, suas utopias). A filosofia do liberalismo, com todas as suas consequentes armadilhas para a autonomia individual e para os direitos naturais do homem, é, na concepção de Scruton, o principal inimigo do conservadorismo, que procura a autoridade acima de tudo e julga que nenhum cidadão possui um direito natural que transcenda sua obrigação de ser governado (SCRUTON, 2015c). É evidente, então, que a ideia do Estado mínimo não é uma causa a ser ferrenhamente defendida por um advogado conservador, pois "nenhum conservador sério pode acreditar que deve haver um poder maior que o do Estado, um poder que pode (caso decida) colocar-se além do alcance da lei” (SCRUTON, 2015c, p. 74-75). De acordo com o escritor britânico, "o papel do Estado é, ou deveria ser, menor do que aquele que os socialistas exigem e maior do que os liberais clássicos permitem" (SCRUTON, 2015b, p. 202). Isso resolveria os conflitos e as tensões aqui discutidas? Creio que não, pois a complexidade da sociedade envolve diversas variáveis que não apenas aquelas relacionadas ao Estado, mas certamente abriria uma possibilidade de diálogo entre as partes permanente e, talvez, mais racional e livre de tanta passionalidade.

Em relação à economia, Scruton é bem claro: "o racionalismo na economia é irracional" (SCRUTON, 2015b, p. 87), até porque "o equívoco de reduzir a ordem política às operações do mercado equipara-se ao erro do socialismo revolucionário de reduzir a política a um plano" (SCRUTON, 2015b, p. 38).

Mas, então, o que vem a ser a liberdade no pensamento conservador? Pelo menos, pode-se afirmar que "liberdade não é o direito absoluto e desimpedido que alguém tem de 
GOMES, D. C. Tensões e conflito de visões: a liberdade a partir dos clássicos ao conservadorismo de Scruton

dizer o que quer e de exprimir seus pontos de vista sobre qualquer coisa, a qualquer momento e em qualquer lugar" (SCRUTON, 2015c, p. 49), característica típica de um liberalismo exacerbado, e que esta "liberdade sem instituições é cega: ela não consolida nem a continuidade social genuína nem a escolha individual genuína. Ela não significa mais que um aceno num vácuo moral” (SCRUTON, 2015c, p. 51). Encontra-se, portanto, uma distância considerável entre o conservadorismo e o liberalismo, pois, "para o conservador, o valor da liberdade individual não é absoluto, mas sujeito a outro valor mais elevado: a autoridade do governo existente" (SCRUTON, 2015c, p. 52).

Essa atitude conservadora perante o Estado requer a permanência de uma ordem civil e a necessidade de independência jurídica como componente essencial, pois a ordem civil certamente é baseada em antecedentes históricos, culturais e sociais. É justamente nessa perspectiva que Scruton aponta a principal falha da visão liberal:

[...] ela baseia toda a política e toda a moralidade em uma ideia de liberdade, mas não provê nenhuma filosofia da natureza humana que possa nos contar aquilo que a liberdade é de verdade ou por que ela é importante. Ela isola o homem da história, da cultura, de todos os seus aspectos não escolhidos, que são, na verdade, as precondições da sua autonomia subsequente. (SCRUTON, 2015c, p. 204-205).

Nessa abordagem conservadora, há uma defesa daquilo que se entende por "herança coletiva" de coisas admiráveis que merecem o empenho em busca de sua preservação. Por isso, "o conservadorismo é a filosofia do vínculo afetivo. Estamos sentimentalmente ligados às coisas que amamos e que desejamos proteger contra a decadência" (SCRUTON, 2015b, p. 53), o que difere frontalmente daquilo que Sowell (2012) apresentou como visão irrestrita, que tende a buscar o máximo de flexibilidade para mudar decisões com base em informações ulteriores, tendo em vista que mudar princípios historicamente desenvolvidos com base nas teorias ou nos estudos das ciências sociais tem sido a característica principal de pensadores sociais modernos adeptos dessa visão.

Nessas circunstâncias, pode-se afirmar que o conservadorismo de Scruton está intimamente relacionado à visão restrita exposta por Sowell? Acredito que não. Porém, diria que ela se distancia mais da visão irrestrita do que da visão restrita, sem, entretanto, desaguar completamente nesta última. O fato é que, de acordo com Sowell, há uma influência darwinista visível na visão restrita, não enquanto "uma teoria da sobrevivência dos indivíduos mais fortes, mas dos processos sociais mais fortes" (SOWELL, 2012, p. 87). Nessa linha de raciocínio, haverá quem diga, de forma equivocada, que os conservadores são darwinistas exacerbados, apesar de a atualidade vir demonstrando que os valores por eles defendidos 
estão em decadência. A história dirá que esses valores foram os mais fortes? Não temos como garantir.

\section{CONSIDERAÇÕES FINAIS}

Ao término deste artigo, depois de discutir sobre as tensões e visões políticas no tocante à liberdade com base em autores clássicos, além de se discutir a respeito da abordagem conservadora de Scruton, entende-se que a dinamicidade e complexidade da condição humana ultrapassam padrões e ideologias políticas que buscam enquadrar a sociedade numa uniformidade não condizente com a pluralidade típica das sociedades modernas, o que torna propício o surgimento de tensões entre visões divergentes. Para minimizar esses conflitos, filósofos políticos do Iluminismo, de Hobbes a Locke, "encontraram as raízes da ordem política e a razão da obrigação política em um contrato social [...], um acordo vinculado a tudo aquilo que os cidadãos sensatos possam consentir" (SCRUTON, 2015b, p. 41-42). Entretanto, numa abordagem conservadora, esse "contrato social requer uma relação de filiação como membro de uma sociedade" (SCRUTON, 2015b, p. 43), isto é, há a necessidade de um sentimento de pertencimento que desloque a escolha apenas do "eu” para o "nós". Essa "livre associação nos é necessária não só porque "nenhum homem é uma ilha', mas porque os valores intrínsecos surgem a partir da cooperação social" (SCRUTON, 2015b, p. 182).

Nesse sentido, a liberdade passa a se basear numa responsabilidade que deve possuir o indivíduo racional que enxerga a sociedade como um território comum, no qual suas escolhas afetam a si mesmo e aos outros. Caso ocorra o desaparecimento daquilo que chamamos de "contrato social", há uma grande probabilidade de se instaurar uma desorientação em que o indivíduo não enxergará linhas ou princípios norteadores em que possa "fincar os pés", mas apenas um caminhar "livre" a lugar nenhum — o que torna relevante ressaltar a importância das instituições e suas leis, que dão sentido aos mais diversos interesses daqueles que são livres, mesmo cientes de que as tensões e os conflitos que emanam das diferentes visões ali presentes não serão extirpados.

\section{REFERÊNCIAS}

ABREU, M. A. A. Conflito e interesse no pensamento político republicano. Tese (Doutorado em Ciência Política) - Universidade de São Paulo, São Paulo, 2008 
GOMES, D. C. Tensões e conflito de visões: a liberdade a partir dos clássicos ao conservadorismo de Scruton

BOBBIO, N. Direita e esquerda: razões e significados de uma distinção política. São Paulo: Editora UNESP, 1995.

HOBBES, T. Leviatã. São Paulo: Martin Claret, 2014.

LOCKE, J. Segundo Tratado sobre o Governo Civil. Petrópolis: Vozes, 2001.

MAQUIAVEL, N. Comentários sobre a primeira década de Tito Lívio. Brasília: UnB, 1982. O príncipe. São Paulo: Escala, 2006.

MARX, K.; ENGELS, F. A ideologia alemã. São Paulo: Martins Fontes, 1998.

MERQUIOR, J. G.O Liberalismo: antigo e moderno. 3. ed. São Paulo: É Realizações, 2014.

MILL, S. Ensaio sobre a liberdade. São Paulo: Escala, 2006.

ROTHBARD, M. Esquerda \& Direita: perspectivas para a liberdade. Campinas: Vide Editorial, 2016.

ROUSSEAU, J.O contrato social. São Paulo: Escala, 2006.

SCRUTON, R. As vantagens do pessimismo e o perigo da falsa esperança. São Paulo: É Realizações, 2015a.

. Como ser um conservador. Rio de Janeiro: Record, 2015b.

O que é conservadorismo. São Paulo: É Realizações, 2015c.

SOWELL, T. Conflito de visões: origens ideológicas das lutas políticas. São Paulo: É Realizações 2012. 